\title{
ADÍLIA LOPES E SYLVIA PLATH: UM CORPO EM DIFERENÇA
}

\section{ADÍLIA LOPES AND SYLVIA PLATH: A BODY IN DIFFERENCE}

Ana Beatriz Affonso Penna ${ }^{1}$

\section{RESUMO}

Este artigo tenciona discutir as obras das poetas Adília Lopes e Sylvia Plath a partir das relações entre corpo e escrita, com um enfoque para as questões de gênero. Para esta discussão, serão utilizadas as reflexões sobre imagem de Henri Bergson e Gilbert Simondon.

PALAVRAS-CHAVE: corpo; escrita; Adília Lopes; Sylvia Plath, gênero.

\section{ABSTRACT}

This article intends to discuss the works of the poets Adília Lopes and Sylvia Plath based upon the relations between body and writing, with focus on gender issues. For this discussion, Henri Bergson's and Gilbert Simondon's reflections on the notion of image will be employed.

KEYWORDS: body, writing; Adília Lopes; Sylvia Plath, gender. 


\section{DAS ESTRUTURAS ENCARNADAS}

Poeta que começa a publicar na metade da década de 80, Adília Lopes, pseudônimo literário de Maria José da Silva Viana Fidalgo de Oliveira, é, como uma significativa parcela de poetas portugueses contemporâneos, uma poeta da zona de cruzamento entre uma dicção conectada a uma cena poética discursiva tradicional e a de uma dicção relacionada a referências à cultura pop, publicidade, cortes cinematográficos, narratividade, linguagem radicalmente coloquial e/ou popular e motivos aparentemente banais. Todavia, chama atenção que, em Adília, o tratamento poético dos diferentes discursos que transcursam a linguagem social pareça perpassar necessariamente pelo lugar de fala de mulher enquanto posição discursiva em seu texto, sugerindo uma espécie de esforço ético tanto para questionar os "saberes discursivamente consignados" (MARTELO, 2004, p. 111) da posição discursiva de mulher, conforme afirma Rosa Maria Martelo em seu artigo "Adília Lopes: ironista”, como também para experimentar as condições do discurso feminino no gênero lírico. Preocupação essa que parece irmanar-se com a de, confessadamente, uma de suas grandes influências poéticas: a poeta americana Sylvia Plath $^{2}$.

Tal como Adília, Sylvia Plath ficou conhecida pelo seu investimento em um aparente pacto biográfico, principalmente naquilo que concerne à aderência entre a imagem da autora mulher à sua persona poética. Seu suicídio em 1963 foi convertido por determinada crítica adepta ao biografismo em evento significador de toda sua obra, reatualizando o que em Plath era procedimento estético: a criação de uma persona literária. De igual maneira, vê-se em Adília a construção de uma crítica presa a uma figura autoral muito marcada pela condição autobiográfica que os seus livros sugerem ${ }^{3}$.

Ainda que em Adília existam sintomas biográficos trançados ao trabalho poético, como, por exemplo, a menção à rua onde habita a autora, e em Sylvia Plath um possível paralelo entre sua obra poética e seu livro The Bell Jar, apenas supostamente autobiográfico, a problemática superinterpretação de dados como biográficos, tanto pela crítica como pela recepção literária, por vezes sugere que a escolha das poetas por consolidarem uma enunciação em feminino nas suas respectivas obras contribui, à revelia da vontade ou do que foi a vontade de suas autoras, para esse fenômeno de superexposição biográfica. Claro que importa aqui lembrar que a necessidade de prender uma obra a um corpo biográfico, negando-lhe o exercício estético do fingimento pessoano, tem por fundo a acepção de que a posição abstrata portadora de uma liberdade radical e universal, conforme aponta Simone de Beauvoir em O segundo sexo, é sempre masculina; enquanto o feminino é um "Outro" fora das normas universalizantes, portanto, inexoravelmente particular e corporificado (BEAUVOIR, 1970, p. 5). Dessa forma, é ainda mais uma vez preciso recordar a lição do texto "A morte do autor”, em que Roland Barthes aponta para a necessária condição da escrita enquanto código transfigurativo e constrangedor de uma determina- 
da representação de real, portanto, para a noção que o sujeito que emerge da linguagem não pode ser concebido enquanto uma pessoa/autor, dado que não existe um sujeito para além da enunciação, para além do código (BARTHES, 1987, p. 58), não havendo assim uma transparência entre um suposto núcleo psicológico interno e a linguagem.

No entanto, detenho-me um pouco mais sobre Barthes, pois lembro que a linguagem não é um sistema de funcionamento autônomo, mas que apenas existe enquanto fenômeno encarnado. Uma necessidade de carne advinda da palavra, que nos faz lembrar que a morte do autor Fernando Pessoa é o limite da linguagem de Álvaro de Campos. E, ainda que não haja indivíduo o qual possa ser integralmente responsabilizado por suas palavras, já que a língua é fascista e obriga a dizer (BARTHES, 1997, p. 16), é, no entanto, pela sua própria carne que o sujeito escreve. Mas no corpo não procuro um refúgio para encontrar a centelha que poderia nos dar o prazer do pleno livre-arbítrio de um sujeito centralizado numa consciência, cuja linguagem obedeceria a essa relação autêntica. Com o corpo recordo que o processo de significação se instituiu nele e através dele. O que significa dizer que, assim como a linguagem verbal inscreve-se num corpo, este corpo não é apenas passivamente inscrito, mas também participa do processo de inscrição, cravando ruídos ${ }^{4}$ na feitura desse processo. De forma que não existem regimes de significação enquanto estâncias abstratas à prova de vida. Afinal, se o emaranhado de significações que a um corpo é imposto transforma-se na relação com seus ruídos, não há como presumir que essas significações chegaram puras de interferências corporais, uma vez que as significações só existem e apossam outros corpos quando encarnadas. Assim, se antes este argumento foi utilizado para pensar a questão da agência de um corpo na construção do gênero, agora o levamos para questionar as estruturas descorporificadas da linguagem verbal em Barthes. Com isso quero dizer que a escrita não é apenas o desvelamento de um sistema incorpóreo, e que há um imenso paralelo entre o procedimento que Barthes caracteriza como o único poder do escritor, "o de misturar as escritas, de as contrariar umas às outras, de modo a nunca se apoiar numa delas" (BARTHES, 1987, p. 58), e o procedimento como um corpo faz comparecer seus ruídos no processo de significação. Se a língua obriga dizer, ela não obriga todos a dizerem da mesma forma. Não se trata, portanto, de reivindicar para a linguagem poética a volta da pessoa/autor enquanto núcleo de coerência subjetiva e arbítrio sobre uma linguagem, mas de reivindicar a existência de um corpo na enunciação, o que nos gera uma série de questões sobre os impactos na escrita daquilo que acontece a um corpo.

Contudo, quero deixar claro que não intento resgatar a tradicional via do biografismo como recurso para interpretações literárias. Entre o que acontece a um corpo e a sua expressão em linguagem há sempre um desnível, mesmo nas falas mais cotidianas ${ }^{5}$. Em literatura, o desnível torna-se uma dicção. Consequentemente, uma prática de significação que formaliza o desnível entre o que acontece a um corpo e sua possibilidade de 
enunciação na linguagem não pode ser da ordem da biografia como costumeiramente é entendida. Ler um texto a partir de uma relação identidade-corpo de um autor, ou seja, pela sua figura pública, é impor continuidades discursivas e corporais, como também impor continuidades entre esferas discursivas e corporais, ou seja, é impor um modo de leitura sobre a grafia de um corpo. E quando digo grafia de um corpo não necessariamente aponto para a relação de uma escrita que ambiciona escrever o corpo individual que lhe é suporte, mas para a questão de ser uma escrita promovida por um corpo, que o tem como condição, isto é, assinalar a escrita como um processo de significação que se faz com um corpo. De forma que, se não nos é possível cogitar um corpo pré-significação, o mesmo se pode dizer de uma significação pré-corpo. Também não faz parte do meu projeto estabelecer uma espécie de determinismo entre linguagem poética e a posição que um corpo ocupa, primeiro porque o processo de significação é um movimento incessante, sendo todas as posições fixas uma ficção de efeitos; segundo porque, se toda a enunciação é um modo - ainda que precário de habitar o real, e digo habitar e não entender, não acessar nem espelhar o real, a literatura é esse lugar onde se pode explorar habitações por enunciações não próprias, experimentar pelos usos sintáticos, paradigmáticos e semânticos estrangeiros, sentidos vinculados a um corpo que não é seu. Mas lembremo-nos que ninguém se banha no mesmo rio duas vezes, e que acessar sentidos de outro corpo é desestabilizar a noção de próprio.

Voltemos nosso olhar para o caso Sylvia Plath e Adília Lopes, para a escolha das poetas por efeitos que emulam a posição discursiva socialmente reconhecida enquanto feminina ${ }^{6}$, posição essa que coincide com a dos corpos e respectivas figuras públicas das autoras. Tal procedimento de não ruptura entre gênero biográfico e lugar de escrita poética está longe de ser inovador, já que, na tradição moderna, a maior parte dos poetas não descolam seu gênero biográfico masculino do gênero de sua enunciação poética $^{7}$. No entanto, no caso específico das poetas mencionadas, parece-me que a prática da escrita poética, essa mistura de escritas de que Barthes nos fala, está marcada por um impasse, que é o caráter masculinista da literatura canônica, o qual, como já mencionado, interdita ou invisibiliza uma série de práticas textuais significantes ligadas a posições e atividades discursivas não apropriadas à performance do gênero masculino. Em vista disto, penso haver por parte das autoras uma percepção de que diversas práticas textuais relacionadas ao seu gênero biográfico - e, como consequência, à significação dos seus corpos - não pertencem ao campo da expressão literária, ou seja, são escrituras interditadas, não misturáveis, o que gera em suas escritas a noção de um corpo em diferença. Esse corpo em diferença, enquanto construto densamente habitado por efeitos de gênero, leva-as a refletir em poesia a respeito da própria condição complexa que o corpo experimenta enquanto simultaneamente lugar de percepção e lugar a ser percebido. 


\section{DAS IMAGENS E CORPOS}

A procura pela verdade ou o real em filosofia constantemente foi acompanhada pela discussão sobre os métodos ou pressupostos os quais configurariam o modo desta procura, isto é, um questionamento sobre as possibilidades de erigir um conhecimento sobre o real. Grosso modo, na filosofia ocidental, vê-se a presença de vertentes que, à primeira vista, possuem acepções contrárias a respeito das condições de acesso à coisa em si: numa, acredita-se que o universo/objeto existe fora de nossa percepção; e noutra, o universo/objeto existe apenas a partir de nossas percepções. $\mathrm{O}$ filósofo Henri Bergson não irá tratar desta questão sem antes fazer uma denúncia metodológica. Para ele, perguntar se o universo existe apenas em nossa percepção ou fora dela seria

[...] enunciar o problema em termos insolúveis, supondo-se que sejam inteligíveis; é condenar-se a uma discussão estéril, em que os termos pensamento, existência, universo serão necessariamente tomados, por uma parte e por outra, em sentidos completamente diferentes. Para solucionar o debate, é preciso encontrar primeiro um terreno comum onde se trava a luta, e visto que, tanto para uns como para outros, só apreendemos as coisas sob forma de imagens, é em função de imagens, e somente de imagens, que devemos colocar o problema (BERGSON, 1999, p. 21).

No prefácio escrito em 1910 a Matéria e memória, Bergson diz que seu livro é abertamente dualístico, uma vez que afirma "tanto a realidade da matéria como a realidade do espírito" (BERGSON, 1999, p. 26). Ao colocar o problema da percepção como uma questão de imagem, o filósofo procura uma posição intermediária entre o que denomina realismo e idealismo. Isto é, a matéria não está mais enclausurada por sua representação ${ }^{8}$ ou pela sua inacessibilidade, visto que o pensamento sobre a percepção enquanto um movimento do sujeito para o objeto, ou do objeto para o sujeito, é revisto para um movimento duplo, em que sujeito e objeto são condicionantes da feição das imagens, sendo a imagem menos do que uma coisa mas mais do que uma representação (BERGSON, 1999, p. 27).

A proposta de Bergson apela para uma noção de comunicabilidade, que posteriormente continuará a ser desenvolvida por outros pensadores, como Gilbert Simondon. No prefácio de seu livro Imaginación e invención, Simondon percebe a imagem mental como um elemento proveniente do processo de interação entre o organismo e o meio. Contudo, Simondon recusa dar ao sujeito um controle imaginante sobre as imagens, apontando justamente para como as imagens podem se negar a obedecer às vontades dos sujeitos, inclusive os perturbando psiquicamente:

De fato, as imagens não são tão límpidas como conceitos; não obedecem com tanta ductilidade à atividade do pensamento; somente se pode as governar de maneira indireta; conservam certa opacidade como uma população estran- 
geira no seio de um estado bem organizado. Contendo em certa medida vontade, apetite e movimento, aparecem quase como organismos secundários no seio do ser pensante: parasitas ou coadjuvantes, são como mônadas secundárias que habitam em certos momentos o sujeito e o abandonam em outros $^{9}$ (SIMONDON, 2013, p.15).

Em contrapartida, segundo Simondon, tampouco as imagens seriam apenas percepções de fenômenos sensoriais, nem corresponderiam a um concreto puro. Para o pensador, haveria um aspecto semiconcreto das imagens que estaria entrelaçado com conteúdos afetivos e cognitivos (SIMONDON, 2013, p.16). Neste entre-lugar da imagem, haveria também algo de profundamente social em sua feitura e circulação, já que o autor admite que existem agrupamentos estáveis e moventes de imagens que, materializados, constituem parte da realidade social de certas populações:

Em verdade, a imagem, como realidade intermediária entre o abstracto e o concreto, entre o eu e o mundo, não é somente mental: ela se materializa, se converte em instituição, produto, riqueza, se difunde tanto pelas redes comerciais como pela "mass media" que difundem a informação ${ }^{10}$ (SIMONDON, 2013, p. 19).

O empreendimento epistemológico de Bergson e Simondon, por enfrentar as dicotomias entre sujeito e objeto, abstrato e concreto, percepção e matéria, faz-nos pensar o corpo enquanto base de comunicabilidade entre os dualismos apresentados, ou seja, é ele evidência de que a matéria afeta nossos modos de perceber, como também de que a percepção, não só em sua acepção sensorial, afeta nosso conhecimento da matéria ${ }^{11}$. Isto é, o corpo é esse lugar simultâneo de produção e recepção de imagens. Se existe um eu que tem percepções de seu corpo, existe um corpo cujos processos ancoram a percepção de um eu, o que nos leva a reconhecer que há no termo autoimagem corporal, naquilo que diz respeito ao entrecruzamento de percepção e matéria para a fabricação de uma imagem, uma astúcia. Contudo, este entrecruzamento de percepção e matéria não geraria imagens harmonicamente fixas, visto que ele é um processo de tensão contínua entre duas esferas irredutíveis, em que a matéria resiste a ser englobada a um domínio perceptivo e a percepção a um domínio material.

Agora levemos este problema para uma reflexão de linguagem verbal. Mas não tão rápido, pois o lugar da imagem não é o mesmo do verbo, ou seja, não elenquemos a linguagem verbal como estrutura à qual toda prática de significação se subjuga. Até porque, conforme afirma Gottfried Boehm em seu texto "Aquilo que se mostra. Sobre a diferença icônica”, a prioridade do discursivo como princípio estruturante remonta a $50 \mathrm{mil}$ anos atrás, enquanto que representações pictóricas já existiam há mais de 200 mil anos, e a criação de artefatos (uma arma de pedra, por exemplo), há pelo menos um milhão de anos (BOEHM, 2015, p. 31), o que significa dizer que as imagens mentais têm uma longa vida anterior à estruturação 
pela palavra, não sendo, portanto, reduzíveis a ela. No entanto, em semelhança com a imagem, a linguagem parece lidar necessariamente com os entrecruzamentos entre matéria e percepção, sendo uma das suas grandes preocupações as formas como um corpo percebe a si mesmo num espaço. No mesmo texto citado, Gottfried Boehm assinala o trabalho do linguista austríaco Karl Bühler, o qual estabeleceu o papel essencial dos dêiticos para a linguagem verbal, apontando que "no espaço motor do gesto, com seu vai e vem, se estabelece já a diferença entre 'aqui' e 'lá'” (BOEHM, 2015, p. 31), provando-se que "toda dêixis, seja ela codificada e arbitrária, supõe uma localização de um locutor encarnado" (BOEHM, 2015, p. 32). Igualmente, vale ainda lembrar que a linguagem verbal, mesmo quando martelada na cabeça, apenas faz mentalmente sentido pela emulação da enunciação oral ou das marcas gráficas da letra, isto é, através de inscrições corpóreas.

Dessa forma, se a relação da linguagem verbal com a voz, o gesto, o digitar, o traçar dos dedos é o sintoma mais imediato do vínculo desta com o corpo material e suas imagens no processo de formalização e construção de sentidos, não podemos nos esquecer de que há também um paralelo entre as imagens poéticas e as imagens mentais. Demonstrativo disto são os constantes relatos por parte dos poetas sobre o desejo de formalizar em palavras uma ideia, uma sensação, uma cena, isto é, uma experiência de significação do sensível que não é da ordem estruturante do discurso verbal. Assim, se o corpo é uma prática textual discursiva, no sentido de que é um tópos no discurso, é importante lembrar que mesmo seu processo de significação verbal não se restringe apenas à influência do sistema linguístico. A multiplicidade das práticas de significação do sensível, abrangendo gestos, atuações, aspectos sonoros, pictóricos e táteis, faz do corpo um lugar rico de produção e recepção de imagens e, consequentemente, de significações. De modo que dizer verbalmente um corpo é friccioná-lo constantemente contra as imagens ${ }^{12}$ que produz, intercepta e reinscreve, sendo elas próprias frutos do tensionamento contínuo entre percepção e matéria. Isto é, pensar a grafia de um corpo, dada a problematização das condições de conhecimento da matéria e percepção, é, assinalar a escrita como um processo de significação que perpassa a questão das imagens.

\section{DA RELAÇÃO COM A VIOLÊNCIA, UM SENTIDO IRREDUTÍVEL}

Dizíamos que, em Adília Lopes e Sylvia Plath, há textualmente a inscrição de um corpo em diferença. Diferença, claro, entre a enunciação lírica canônica, pois masculina; porém, não só. Ainda mais uma vez, cito Gottfried Boehm, em seu texto "Aquilo que se mostra. Sobre a diferença icônica", em que o autor assinala que "uma imagem sem contraste é inconcebível", uma vez que "mesmo uma imagem perfeitamente monocromática tira sua iconicidade de uma diferença” (BOEHM, 2015, p. 28). No texto, estamos diante de imagens pictóricas, mas, ainda assim, o argumento é pensável para o problema do corpo. A maior parte do tempo, o sujeito 
lida com uma espécie de continuidade em relação ao corpo, até porque, se interceptada a possibilidade de alma, o corpo é a ancoragem do sujeito. A dor, as necessidades vitais por comida, sono e defecar são rupturas nessa continuidade corporal do sujeito, as quais promovem um estranhamento do corpo em relação à percepção. Contudo, principalmente depois de enunciar as leituras promovidas por Bergson e Simondon, atento para o fato de que não se trata de reafirmar a separação entre sujeito e seu corpo, como se os processos perceptivos de uma consciência não fossem em alguma medida também dispositivos corporais. Mas interessa-me apontar para esse processo do corpo que precisa alterizar sua própria matéria para se perceber, em contraste. Assim como nós só percebemos nosso formato da língua, sua experiência táctil, contra o contato de uma outra, ou contra nosso próprio dedo (objetificado em instrumento), ou contra o alimento que depositamos na boca. Desse forma, podemos pensar que o corpo conhece-se por um outro, um outro que, ao ser percebido, faz com que o corpo que experimenta se perceba, em diferença. Tal fenômeno, em que o próprio e o outro surgem simultaneamente por uma relação de contato, em que aquilo que o outro corpo não pode reduzir a seu é uma diferença ontologicamente instauradora, é passível de ser visto em semelhança com o que falávamos do processo de fabricação de imagens. Se pensarmos numa pessoa cega, a qual com sua mão tateia uma bola vermelha, constatamos que se estabelece uma aliança entre o tato e o formato arredondado da bola, aliança essa que não se repete entre o olhar e o vermelho. Por mais que entre o olho e a cor não tenha existido uma comunicabilidade, isso não faz com que a bola deixe de ser vermelha, o que a princípio contribuiria com a tese realista. No entanto, os idealistas poderiam argumentar que o vermelho, como não pode ser percebido, é impossível de ser conhecido, sendo, portanto, a percepção o que determina a nossa forma mundo. Mas há ainda mais um aspecto. A mão percebe a bola enquanto arredondada porque há na bola algo passível de comunicar este arredondamento e há na mão algo passível de percebê-lo. Ou seja, o arredondado é algo pertencente à relação mão-bola, isto é, ele não pode ser reduzido a um dos elementos dessa relação. Ao mesmo tempo que é à comunicabilidade existente entre uma mão e uma bola que o arredondado deve seu status ontológico, essa comunicabilidade se faz em diferença, na irredutibilidade da mão à bola e vice-versa ${ }^{13}$. Assim é a imagem.

Se o corpo simultaneamente é lugar de percepção e lugar a ser percebido, lugar de alteridade e reconhecimento, o corpo verbal de Sylvia Plath e Adília Lopes realiza-se dentro deste movimento de tensão, em que os pressupostos que ancoram o processo de conhecimento do corpo são encenados. Dessa forma, vê-se a construção verbal de imagens corporais que fazem girar uma gama de significações tanto discursivas como não discursivas, as quais envolvem os processos de feitura e reconhecimento do corpo, em que têm especial lugar os agrupamentos de imagens corporais que foram materializadas em instituições. 
A fim de dar prosseguimento a essa análise, leio o terceiro poema do livro de Lopes, A pão e água de colónia, de 1987, o qual pode nos servir como uma espécie de arte poética, onde Adília fala-nos de sua Musa e da relação sacrificial que esta lhe impõe. Transcrevo-o integralmente:

A minha Musa antes de ser
a minha Musa avisou-me
cantaste sem saber
que cantar custa uma língua
agora vou-te cortar a língua
para aprender a cantar
a minha Musa é cruel
mas eu não conheço outra
(LOPES, 2014, p. 30)

O recurso que me salta à primeira leitura é o uso das repetições como dispositivo de sentido. "A minha Musa" do primeiro verso, já no segundo, apesar de idêntica na repetição nominal, não mais possui o mesmo referente. Antes de cortar-lhe a língua, "a minha Musa" era outra coisa que não "a minha", pois o gesto que realiza a relação é o corte sacrificial. No entanto, ainda que o eu-lírico situe-nos diante de duas Musas - uma minha pelo sacrifício e outra anterior à relação, a Musa não própria só existe textualmente enquanto "a minha”. Penso nos discursos prosaicos e nas vezes em que contei aos amigos, por exemplo, sobre o passado de meu animal de estimação antes de ele ser meu. Meu ele aparece na fala, pois todo o seu passado não pertencido, após tornar-se parte minha, só pode ser lido através do seu pertencimento. Este pertencimento obviamente pode passar-se pelo viés autoritário da propriedade, em que a posse se faz apenas em uma direção - apenas eu tenho o animal de estimação, ele não me tem -; entretanto, há a possibilidade de que ele se faça pelo afeto, em que, da mesma forma que eu tenho o animal, o animal me tem, como acontece aos namorados, os quais, para que sejam nossos, precisamos ser deles. Dessa maneira, abre-se ao poema a possibilidade de ler a relação do eu-lírico com a Musa tanto como uma relação autoritária, em que apenas uma das partes detém a outra, ou como uma relação de afetos recíproca, em que ambas as partes se possuem. Opto por ler de maneira atravessada, pois percebo que uma relação de afetos, ainda que em certa medida possa ser reconhecidamente recíproca, possui graus de reciprocidade e relações de poder não balanceadas em seu interior. Claro que aqui não podemos esquecer o que a Musa tradicionalmente significa para a poesia em termos de autoridade, de obediência a um discurso que converge todos seus exteriores a um pertencimento. "A minha Musa é cruel", e para cantar, para que a Musa se realize enquanto "minha”, ela "custa uma língua”. Ou seja, em Adília, o eu-lírico não canta impunemente.

Não é a primeira vez que na poética de Adília recorre-se aos temas da proibição e da transgressão moral, os quais são frequentemente relacionados à sexualidade. Basta lembrar de poemas como "Desobediência castigada" ou a segunda parte do livro $O$ decote da dama de espadas, inti- 
tulada "As meninas exemplares". A ideia de castigo é recorrentemente resgatada, associada aos contos infantojuvenis ou à literatura historicamente reservada às mulheres, com o intuito de separar as más das boas meninas, ainda que muitas vezes haja no poema uma contestação desse julgamento. Esta contestação que se dá a priori como já malograda não deixa de conter uma forma de prazer que se excita com o castigo ou proibição destinados à transgressão e, posteriormente, com o malogro da contestação, o qual dimensiona uma ideia ainda maior de justeza para a transgressão. Mas por que compactua o eu-lírico com o jogo perverso da Musa?

Lembro-me de Sylvia Plath, mais especificamente do poema "The Courage Of Shutting-Up”, de seu livro Ariel. Começo a pensar que o corte perverso que Lopes opera não lhe é exclusivo. Transcrevo o poema de Plath:

The courage of the shut mouth, in spite of artillery!

The line pink and quiet, a worm, basking.

There are black disks behind it, the disks of outrage,

And the outrage of a sky, the lined brain of it.

The disks revolve, they ask to be heard -

Loaded, as they are, with accounts of bastardies.

Bastardies, usages, desertions and doubleness,

The needle journeying in its groove,

Silver beast between two dark canyons,

A great surgeon, now a tattooist,

Tattooing over and over the same blue grievances,

The snakes, the babies, the tits

On mermaids and two-legged dreamgirls.

The surgeon is quiet, he does not speak.

He has seen too much death, his hands are full of it.

So the disks of the brain revolve, like the muzzles of cannon.

Then there is that antique billhook, the tongue,

Indefatigable, purple. Must it be cut out?

It has nine tails, it is dangerous.

And the noise it flays from the air, once it gets going!

No, the tongue, too, has been put by,

Hung up in the library with the engravings of Rangoon

And the fox heads, the otter heads, the heads of dead rabbits.

It is a marvelous object -

The things it has pierced in its time.

But how about the eyes, the eyes, the eyes?

Mirrors can kill and talk, they are terrible rooms

In which a torture goes on one can only watch.

The face that lived in this mirror is the face of a dead man.

Do not worry about the eyes -

They may be white and shy, they are no stool pigeons,

Their death rays folded like flags 
Of a country no longer heard of,

An obstinate independency

Insolvent among the mountains ${ }^{14}$.

(PLATH, 2007, p. 24)

Diferente do poema de Adília Lopes, em que o pronome possessivo e oblíquo e a desinência do verbo apresentam marcas textuais de uma enunciação em primeira pessoa, isto é, a existência de um eu que se implica no que enuncia, no poema de Plath não há vestígios textuais dessa primeira pessoa, ainda que toda locução envolva tomar para si a posição de um $\mathrm{eu}^{15}$. Já na primeira leitura do poema, percebe-se a encenação de um corpo, em que são abundantes as imagens corporais relacionadas à violência. A cena, inscrita nas imagens de um corpo exuberante ("silver beast", "dark canyons", "fox heads", etc.) corrobora para a construção de uma ideia disruptiva de beleza que partilha com a violência a noção de corte. A língua, "the line pink and quiet, a worm, basking", encontra-se imobilizada. Foi cortada fora e agora, junto a prêmios de caça, está pendurada numa biblioteca, um espaço de institucionalização e desvitalização. Reprimida, busca outras vias. $\mathrm{O}$ silêncio, que tradicionalmente foi ligado a uma ideia de submissão, na escrita do poema revela-se uma prática resistente ao demonstrar que ausência de som nunca foi ausência de expressão, e que, aquilo que o verbo cala, os olhos manifestam com o prazer "Of a country no longer heard of,/An obstinate independency/Insolvent among the mountains". E é também sintomático que o título inicial "The Courage Of Quietness" tenha sido mudado para "The Courage Of Shutting-Up", agregando uma noção de agência e agressividade não existente no vocábulo "quietness".

A noção de corte, presente tanto no poema de Adília como no de Plath, possui algumas consequências aproximáveis de sentido. A língua mutilada ocupa um lugar central na maquinaria de ambos os textos, desempenhando um papel metonímico em relação à linguagem verbal. Metonímia que não reduz a palavra a apenas um sentido, permanecendo no vocábulo seu significado corporal. Desse modo, esta simultânea metonímia do corpo e da linguagem verbal operada pela palavra língua aponta uma relação entre essas duas esferas. Em Adília Lopes, a língua é um dispositivo do canto, e mesmo o fato de ser cortada por uma autoridade (a Musa) não impede o eu-lírico de cantar. Em Plath, a língua é, como o corpo como um todo, um aparelho significante ${ }^{16}$ emudecido, ainda que os olhos no poema consigam resistir a esse silenciamento. Desse modo, observa-se que as interdições de linguagem materializam-se nos poemas em violências contra os corpos. No entanto, se nos poemas o silenciamento do corpo não intercepta a capacidade que este tem de significar, em contrapartida, essa violência é incorporada ao horizonte de sentido desses corpos. Ao confrontá-los contra a violência da linguagem, o corpo constrói-se em relação a essa violência. Da relação com essa violência surge um sentido, que não se reduz à ordem da violência, como também não se reduz à ordem de um corpo pré-trauma. 
Ainda que a proposta textual por uma produção de sentidos corporais através da imagem de uma agressão seja um processo difícil, visto que a violência tem como fim impor um lugar para os outros elementos da relação, tanto em Plath como Adília o comparecimento de um princípio de prazer na inscrição de imagens corporais marcadas por processos violentos pode ser lido enquanto uma transgressão que perverte a lógica objetificadora de uma linguagem violenta contra um corpo. Transgressão essa que rejeita figurar os corpos apenas como efeito passivo de uma violência, como também figurá-los pelo uso de agrupamentos imagísticos estáveis presentes no tratamento do corpo feminino no cânone literário. Ou seja, em ambas as poetas encena-se um jogo de contraposição imagética entre corpos de distintos sentidos, em que a presença de certas imagens na superfície textual confronta-se com um outro horizonte imagético de sentido que virtualmente está implicado no texto. No entanto, não há nos poemas um ponto de viragem pleno, a contraposição imagética de corpo contra corpo é um procedimento de conhecimento em diferença, processo em que, como mencionamos, um corpo conhece-se por um outro que, ao ser percebido, faz com que o corpo que experimenta se perceba em contraste. E lembremos ainda mais uma vez que estamos falando aqui de um processo extremamente difícil e consequente, afinal, como já alertava Simondon, as imagens não obedecem com docilidade ao sujeito e o pensamento (SIMONDON, 2013, p. 15), em especial quando são elas relacionadas à violência. Portanto, a recusa de Plath por utilizar textualmente a primeira pessoa, negando-se a implicar um eu nas imagens corporais descritas, e a escolha de Lopes por grafar um corpo mutilado pela linguagem precisam ser lidas como demonstrativas das dificuldades de textualmente significar um corpo que está em violento desacordo entre como é significado, como se significa e os modos de significação.

\section{REFERÊNCIAS BIBLIOGRÁFICAS}

BARTHES, Roland, O rumor da língua (or. Le Bruissement de la Langue, 1984), trad. António Gonçalves, Lisboa, Edições 70, 1987. Aula. 7. ed. São Paulo: Cultrix, 1997.

BEAUVOIR, Simone de. O segundo sexo. Fatos e Mitos (Vol. 1). 4.ed. São Paulo: Difusão Européia do Livro, 1970.

BERGSON, Henri. Matéria e memória. Trad. Paulo Neves. São Paulo: Martins Fontes, 1999.

BOEHM, Gottfried. Aquilo que se mostra. Sobre a diferença icônica. In: ALLOA, Emmanuel (Org). Pensar a imagem. Belo Horizonte: Autêntica Editora, 2015.

BUTLER, Judith. Problemas de gênero: feminismo e subversão da identidade. Trad. Renato Aguiar. Rio de Janeiro: Editora Civilização Brasileira, 2003. 
. Como se faz um poema? [resposta a um inquérito], Inimigo Rumor: Revista de Poesia - Edição Especial: 10 anos de Inimigo Rumor, no 20, Rio de Janeiro e São Paulo, 7 Letras e Cosac Naify, 2008, p. 109-110, [publicado originalmente em Relâmpago, no 14, Fundação Luís Miguel Nava, Lisboa, Relógio D \Água, 2004, p. 29-30. Disponível em: http://cercarte.blogspot.com.br/2009/05/como-se-faz-um-poema-adilia-lopes.html

MARTELO, Rosa Maria. Adília Lopes: ironista. In: SCRIPTA, Revista do Programa de Pós-graduação em Letras e do Cespuc, Pontifícia Universidade Católica de Minas Gerais, Vol. 8, n. ${ }^{\circ}$ 15, 2. ${ }^{\circ}$ semestre de 2004. p. 106-116.

As armas desarmantes de Adília Lopes. A Forma Informe, Lisboa: Assírio e Alvim, 2010, p. 235-252.

PLATH, Sylvia. Ariel. Trad. Rodrigo Garcia Lopes e Maria Cristina Lenz de Macedo. São Paulo: Verus Editora, 2007.

SIMONDON, Gilbert. Imaginación e invención (1965-1966). Trad. Pablo Ires. Buenos Aires: Editorial Cactus, 2013.

Recebido para publicação em 21/11/2016

Aprovado em 07/03/2017

\section{NOTAS}

11Ana Beatriz Affonso Penna é doutoranda em Literatura Comparada pela Universidade Federal Fluminense e professora substituta no Departamento de Letras e Comunicação da Universidade Federal Rural do Rio de Janeiro.

2 Em 2004, a revista Relâmpago realizou um dossiê em torno da pergunta "Como se faz um poema?". Entre os dezoito poetas que responderam a este inquérito encontrava-se Adília Lopes, a qual, ao abordar o processo de sua criação poética, também mencionou suas influências literárias: "As minhas grandes influências, que admito e reconheço, são Sophia, Ruy Belo e Sylvia Plath. Foi com eles que comecei a escrever e é com eles e por eles que continuo a escrever e a ler" (LOPES, 2008, 109).

3 “[...] a recepção da sua obra tornou-se uma questão delicada. Num poema de Clube da Poetisa Morta, Adília escrevia 'Sou uma personagem / de ficção científica / escrevo para me casar', e aludindo a este poema valter hugo mãe, leitor assumidamente apaixonado pela poesia adiliana, organizou uma antologia intitulada Quem Quer Casar com a Poetisa? - título que põe bem em evidência o quanto a afirmação de ficcionalidade dos primeiros versos do poema citado no intitulado da antologia não chegava para impedir a contratualização autobiográfica imposta pela generalidade da obra. Darei ainda dois exemplos que são dois títulos de textos críticos sobre obras de Adília Lopes: 'As Lenga-lengas da Menina Adília'; 'A menina que usava uma Bic a bordo do Titanic' (MARTELO, 2010, p. 214).

4 A escolha da palavra ruídos marca meu interesse por apontar interferências corporais no processo de significação.

5 Um exemplo são os programas de auditório do tipo Casos de família. É comum que, neles, várias das pessoas entrevistadas apresentem dificuldade de expressar em palavras os fatos que lhes aconteceram. São frequentes as repetições exaustivas, a recorrência a lugares-comuns da linguagem popular ou televisiva. Claro que a baixa escolaridade e a exposição às câmeras são fatores indissociáveis; no entanto, esses exemplos evidenciam 
o procedimento de cópia e colagem na tradução de uma narrativa emocional, demonstrando a precariedade própria do lugar que um corpo ocupa com as palavras - ainda que a maior experiência com uma quantidade de artifícios de linguagem recalque a precariedade dessa relação.

6 Em primeira leitura, o uso da desinência, suas flexões gramaticais e a escolha vocabular são os efeitos de marcação do gênero na escrita mais imediatos.

$7 \mathrm{Na}$ experiência da heteronímia pessoana há apenas uma ruptura entre gênero biográfico e heterônimos.

8 Uso a palavra representação como consequência de um trabalho elaborado pela percepção de um ou mais sujeitos para um objeto.

9 De hecho, las imágenes no son tan límpidas como conceptos; no obedecen con tanta ductilidad a la actividad del pensamiento; solo se las puede gobernar de manera indirecta; conservan cierta opacidad como una población extranjera en el seno de un estado bien organizado. Conteniendo en cierta medida voluntad, apetito y movimiento, aparecen casi como organismos secundarios en el seno del ser pensante: parásitas o coadyuvantes, son como mónadas secundarias que habitan en ciertos momentos el sujeto y lo abandonan en otros (SIMONDON, 2013, p.15).

10 En efecto, la imagen, como realidad intermediaria entre lo abstracto y lo concreto, entre el yo y el mundo, no es solo mental: ella se materializa, se convierte en institución, producto, riqueza, se difunde tanto por las redes comerciales como por los "mass media" que difunden la información (SIMONDON, 2013, p. 19).

$11 \mathrm{O}$ velho experimento de colocar a mão direita na água fria e a esquerda na água quente para depois pôr ambas na morna e ter sensações térmicas distintas demonstra o sentido não absoluto e relacional de nossas percepções. Se este experimento foi tomado pelos materialistas para afirmar como as nossas percepções não são confiáveis, também o foi pelos idealistas para declarar como, em verdade, é pelas percepções que acessamos o mundo, sendo, portanto, impossível conhecer a matéria senão pelas percepções. No entanto, se os realistas não se dão conta de que o acesso à matéria sem nenhum condicionamento perceptivo é uma fantasia, pelo outro lado esquecem-se os idealistas de observar que o corpo que se aquece ou esfria com a água condiciona a percepção da próxima matéria, ressaltando-se assim também a dependência das percepções em sua relação com a matéria.

12 Pensemos aqui as imagens segundo as acepções de Bergson e Simondon.

13 Faz-se necessário também assinalar que o arredondado é experimentado em virtude do horizonte de formas triangulares, quadriculares, ou seja, formas contrastantes, e que mão e bola não são entidades essenciais, o que impossibilita a essencialidade das imagens.

14 Tradução de Rodrigo Garcia Lopes e Maria Cristina Lenz de Macedo:

A coragem da boca fechada, apesar da artilharia!

A linha rósea e quieta, um verme, exposto ao sol.

E há discos negros por trás, discos do ultraje,

E o ultraje de um céu, e os discos de seu cérebro.

Os discos giram, querem ser ouvidos -

Carregados, como estão, de adultérios.

Adultérios, maus-tratos, deserções e hipocrisia,

A agulha viajando em sua ranhura,

Fera prateada entre dois cânions escuros,

Um grande cirurgião, um tatuador agora,

Tatuando mais e mais as mesmas tristes queixas,

As cobras, os bebês, as tetas

Nas sereias e garotas de sonho.

O cirurgião está calado, não fala nada.

Já viu muitas mortes, suas mãos estão repletas.

Assim giram os discos do cérebro, como bocas de canhão.

E há aquela foice antiga, a língua,

Incansável, roxa. Deve ser cortada fora? 
Tem nove caudas, é perigosa.

E o barulho que rouba do ar, quando começa.

Não, a língua também foi deixada de lado

Pendurada na biblioteca entre gravuras de Rangoon

E cabeças de raposas, lontras e coelhos mortos.

É um objeto maravilhoso -

Quantas coisas penetrou em outros tempos!

Mas e os olhos, os olhos, os olhos?

Espelhos matam e conversam, são quartos terríveis

Onde a tortura prossegue e só se pode olhar.

O rosto que habitava este espelho é o de um homem morto.

Não se preocupe com os olhos -

Podem ser brancos e tímidos, não são delatores,

Seus raios mortais se dobraram como bandeiras

De um país que não se conhece mais,

Uma independência obstinada

Insolvente entre as montanhas.

15 Diante da elocução "ele diz, não eu", a posição de um eu precisa ser necessariamente ocupada para dizer que é ele quem diz, não eu. Só enquanto um eu na linguagem, posso dizer.

16 Uso o termo significante no sentido de qualidade daquilo que significa. 